\title{
Optimal extraction, purification and antioxidant activity of total flavonoid from endophytic fungi of Conyza blinii H. Lév
}

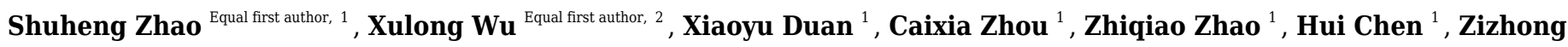 \\ Tang $^{\text {Corresp., } 1}$, Yujun Wan ${ }^{3}$, Yirong Xiao ${ }^{4}$, Hong Chen ${ }^{5}$ \\ ${ }^{1}$ College of Life Sciences, Sichuan Agricultural University, Ya'an, China \\ 2 Chengdu Agricultural College, Chengdu, China \\ 3 Sichuan food fermentation industry research and design institute, Chengdu, China \\ 4 Sichuan Agricultural University Hospital, Ya'an, China \\ 5 College of Food Sciences, Sichuan Agricultural University, Ya'an, China \\ Corresponding Author: Zizhong Tang \\ Email address: 14126@sicau.edu.cn
}

Background. Flavonoid is widely used in the market because of its antibacterial, antiviral, and antioxidant activities. But the production speed of flavonoid is limited by the growth of plants. CBL9 (Chaetomium cruentum) is a Flavonoid-producing endophytic fungi from Conyza blinii H. Lév, which has potential to produce flavonoid. Methods. In this study, we isolated total flavonoid from endophytic fungus CBL9 of Conyza blinii H. Lév using macroporous resin D101. The process was optimized by response surface and the best extraction process was obtained. The antioxidant activities of total flavonoid was analyzed in vitro.Results. It was found that the best parameters were $25^{\circ} \mathrm{C}, \mathrm{pH} 2.80,1.85$ $h$, and the adsorption ratio reached $(64.14 \pm 0.04) \% .60 \%$ ethanol was the best elution solvent. The elution ratio of total flavonoid reached to $(81.54 \pm 0.03) \%$, and the purity was $7.13 \%$, which was increased by 14.55 times compared with the original fermentation broth. Moreover its purity could rise to $13.69 \%$ after precipitated by ethanol, which is very close to $14.10 \%$ prepared by ethyl acetate extraction. In the antioxidant research, the clearance ratio of L9F-M on DPPH, ABTS, $\mathrm{OH}, \cdot \mathrm{O}^{2-},(96.44 \pm 0.04) \%$ and $(75.33 \pm 0.03) \%,(73.79 \pm 0.02) \%,(31.14 \pm 0.01) \%$ at maximum mass concentration, was higher than L9F.Conclusion. The result indicated using macroporous resin in the extraction of total flavonoid from endophytic fungus is better than organic solvents with higher extraction ratio, safety and lower cost. And in vitro test indicated that the flavonoid extracted by macroporous resin have good antioxidant activity, providing more evidence for the production of flavonoid by biological fermentation method. 


\section{Optimal Extraction, Purification and Antioxidant Activity of Total}

\section{Flavonoid from Endophytic Fungi of Conyza blinii H. Lév}

3 Shuheng Zhao ${ }^{1 \dagger}$, Xulong $\mathrm{Wu}^{2 \dagger}$, Xiaoyu Duan ${ }^{1}$, Caixia Zhou ${ }^{1}$, Zhiqiao Zhao ${ }^{1}$, Hui Chen ${ }^{1}$,

4 Zizhong Tang ${ }^{1 *}$, Yujun Wan ${ }^{3}$, Yirong Xiao ${ }^{4}$, Hong Chen ${ }^{5}$

5 1. College of Life Sciences, Sichuan Agricultural University, Ya'an 625014, China

6 2. Chengdu Agricultural college, Chengdu 611130, China

7 3. Sichuan food fermentation industry research and design institute, Chengdu 611130, China

8 4. Sichuan Agricultural University Hospital, Ya'an 625014, China

9 5. College of Food Sciences, Sichuan Agricultural University, Yaan 625014, China

$10 *$ Corresponding author:

11 Zizhong Tang, Tel: +86 0835 2886126; Fax: +86 0835 2886136; E-mail: $\underline{14126 @ \text { sicau.edu.cn }}$

$12 \uparrow$ These authors contributed equally to this work and should be considered co-first authors.

\section{ABSTRACT}

Background. Flavonoid is widely used in the market because of its antibacterial, antiviral, and antioxidant activities. But the production speed of flavonoid is limited by the growth of plants. CBL9 (Chaetomium cruentum) is a Flavonoid-producing endophytic fungi from Conyza blinii H.

Lév, which has potential to produce flavonoid.

Methods. In this study, we isolated total flavonoid from endophytic fungus CBL9 of Conyza blinii H. Lév using macroporous resin D101. The process was optimized by response surface and the best extraction process was obtained. The antioxidant activities of total flavonoid was analyzed in vitro.

Results. It was found that the best parameters were $25^{\circ} \mathrm{C}, \mathrm{pH} 2.80,1.85 \mathrm{~h}$, and the adsorption 
ratio reached $(64.14 \pm 0.04) \% .60 \%$ ethanol was the best elution solvent. The elution ratio of total flavonoid reached to $(81.54 \pm 0.03) \%$, and the purity was $7.13 \%$, which was increased by 14.55 times compared with the original fermentation broth. Moreover its purity could rise to $13.69 \%$ after precipitated by ethanol, which is very close to $14.10 \%$ prepared by ethyl acetate extraction. In the antioxidant research, the clearance ratio of L9F-M on DPPH, ABTS, $\cdot \mathrm{OH}, \cdot \mathrm{O}^{2-}$, $(96.44 \pm 0.04) \%$ and $(75.33 \pm 0.03) \%,(73.79 \pm 0.02) \%,(31.14 \pm 0.01) \%$ at maximum mass concentration, was higher than L9F.

Conclusion. The result indicated using macroporous resin in the extraction of total flavonoid from endophytic fungus is better than organic solvents with higher extraction ratio, safety and lower cost. And in vitro test indicated that the flavonoid extracted by macroporous resin have good antioxidant activity, providing more evidence for the production of flavonoid by biological fermentation method.

Keywords: Chaetomium cruentum; Flavonoid; Macroporous resin; Response surface

\section{INTRODUCTION}

Flavonoid is an important secondary metabolites of plants, who owns diverse pharmacological activities owning to complex structure types (Yonekura-Sakakibara et al., 2019). For example, flavonoid has a strong antioxidant effect on blood circulation and cardiovascular system (Echeverría et al., 2017); Calycosin have significant antiviral activity both in vivo and vitro (Zhu et al., 2009); Most flavonoid has a significant inhibitory effect on the growth of bacteria including Bacillus subtilis, Staphylococcus aureus and Escherichia coli (Yousef et al., 2007; Gadkowski et al., 2019).

Endophytic fungi widely exist in advanced plant. It has obvious host specificity and tissue 
45

46

47

48

specificity (Martin et al., 2013; Carrol et al., 1978). Endophytic fungi is able to produce the same or similar secondary metabolites of the host, including flavonoid with excellent activity (Qiu et al., 2010; Shih et al., 2017; Shou-Jie et al., 2018; Chi et al., 2019). CBL9 is a Flavonoidproducing endophytic fungus from Conyza blinii H. Lév, which belongs to Chaetomium and is used to produce flavonoid with excellent antioxidant effect in vitro (Tang et al., 2020).

Macroporous resins have been used in the extraction of flavonoid widely as a result of its advantages (Du et al., 2012; Li et al., 2012; Chen et al., 2013; Lihu et al., 2018). But macroporous resin has not been used in the endophytic fungi of Conyza blinii H. Lév. currently. The macroporous resin D101 was used to extract the total flavonoids of CBL9 for further uses, and the response surface method was optimized to obtain the best process to extract the total flavonoid of the endophytic fungi of Conyza blinii H. Lév.

\section{MATERIALS AND METHODS}

\subsection{Plant material}

The endophytic fungus CBL9 separated from Conyza blinii H. Lév: Biochemistry and Molecular Biology Laboratory of Sichuan Agricultural University preserved 2.2 Chemical reagents

2, 2-Diphenyl-1-picrylhydrazyl (DPPH, HPLC) was purchased from Yuanye Biotechnology Co. (Shanghai, P. R. China). Ferrous Sulfate Heptahydrate $\left(\mathrm{FeSO}_{4} \cdot 7 \mathrm{H}_{2} \mathrm{O}\right)$, hydrogen peroxide $\left(30 \% \mathrm{H}_{2} \mathrm{O}_{2}\right)$, Pyrogallol and Concentrated hydrochloric acid were purchased from Xilong Chemical Co. (Sichuan, P. R. China). Ascorbic acid and Vitamin C (Vc, AR) were purchased from Sinopharm Chemical Reagent Co. (Shanghai, P. R. China). Other chemicals and solvents used in this study were analytical grade. 
$67 \quad 2.3$ Study on optimization of extraction process of crude flavonoid

68 2.3.1 Preparation of raw mater

69 The flavonoid-producing endophytic fungus CBL9 was inoculated into fresh PDA medium 70 and cultured with shaking at $28^{\circ} \mathrm{C}$ until the mycelial pellets grew to a certain condition (Bacteria

71 is not growing and the concentration of flavonoids in the fermentation broth reaches $10 \mathrm{mg} / \mathrm{L}$ ),

72 then fermentation broth was rotary evaporation at $50^{\circ} \mathrm{C}$ and raw material (L9F) was obtained 73 after freeze-drying.

$74 \quad 2.3 .2$ Ethyl acetate extraction

75 The extraction was conducted by following the method of Saraswaty with slight modifications

76 (Saraswaty et al., 2013). 200mL concentrated fermentation broth was mixed with two times the volume of ethyl acetate to extract the fermentation broth, and repeat extraction three times. Crude flavonoid (L9F-E) was obtained by concentrating by evaporation under freeze-drying.

\subsubsection{Preparation of standard curve}

Sodium nitrite-aluminum nitrate colorimetric method was used to draw rutin standard song by following the method of Tang (Tang et al., 2020). The standard curve equation: A=0.4164C$0.0003\left(\mathrm{R}^{2}=0.9994\right)$.

\subsubsection{Single factor test}

The single factor test method was conducted with slight modifications (Bi et al., 2012) and the Macroporous resin D101 was used (Lihu et al., 2018). First, $1.0 \mathrm{~g}$ wet resin pretreated was put into 15 conical flasks and mixed with certain L9F. Then the mixture was incubated at different temperature, $\mathrm{pH}$ for different time. The adsorption ratio of flavonoid was measured.

2.3.5 Response surface analysis

According to the single-factor study, the Box-Benhnken optimization study was designed (Yu 
90 et al., 2019) with three levels (adsorption time, temperature, and $\mathrm{pH}$ ). The adsorption ratio was

91 chosen as inspection index. Design-Expert was used to analyze based on Box-Benhnken data.

92 Possible mathematical model is:

$93 \quad \mathrm{Y}=\beta_{0}+\Sigma \beta_{\mathrm{i}} \mathrm{x}_{\mathrm{i}}+\Sigma \beta_{\mathrm{ij}} \mathrm{x}_{\mathrm{i}} \mathrm{x}_{\mathrm{j}}+\Sigma \beta_{\mathrm{ij}} \mathrm{x}_{\mathrm{i}}^{2}$

$94 \mathrm{Y}$ is the predicted response value; $\beta_{0}, \beta_{\mathrm{i}}, \beta_{\mathrm{ii}}$ and $\beta_{\mathrm{ij}}$ is the regression coefficient representing the

95 interaction of intercept, linear, squared and two factors; $\mathrm{x}_{\mathrm{i}}$ and $\mathrm{x}_{\mathrm{j}}$ is the independent factor of 96 encoding $(\mathrm{i} \neq \mathrm{j})$.

972.4 Influence of eluent concentration

98 Gradient volume fraction of ethanol-water solution was used to elute saturated adsorbent at a 99 certain flow rate $(1 \mathrm{~mL} / \mathrm{min})$. its purity and elution ratio was measured. The total flavonoid (L9FM) was extracted under optimal condition we got in 2.3.5 and 2.4.

101

102

\subsection{In vitro antioxidant activity assay}

\subsubsection{DPPH radical scavenging assay}

The DPPH radical scavenging activities was collected as previously described in Kaur and Tsimogiannis \& Oreopoulou (Kaur et al., 2020; Tsimogiannis \& Oreopoulou 2005). Vc was used as the standard antioxidant. L9F was separately dissolved in distilled water to prepare flavonoid solutions of different concentrations $(0.01,0.02,0.03 \ldots 0.09$, and 0.10 $\mathrm{mg} / \mathrm{mL}$ ). Equal volume of DPPH solution was mixed with different concentrations of flavonoid solution. The mixture was shaken and then put in a dark place for $30 \mathrm{~min}$. Finally, the absorbance was measured at $517 \mathrm{~nm}$ by a spectrophotometer and each experimental group had 3 parallel controls.

$$
\mathrm{Y}(\%)=\left[1-\left(\mathrm{A}_{1}-\mathrm{A}_{2}\right) / \mathrm{A}_{3}\right] \times 100 \%
$$


$112 \mathrm{Y}(\%)$ is the DPPH radical scavenging activity $\mathrm{A}_{1}$ is the absorbance of the sample with DPPH,

$113 \mathrm{~A}_{2}$ is the absorbance of the sample without DPPH, and $\mathrm{A}_{3}$ is the absorbance of DPPH without the

114 sample.

115 2.5.2 ABTS radical scavenging assay

116 The ABTS radical scavenging activities was collected as previously described in Kaur 117 and Zhang (Kaur et al., 2020; Zhang et al., 2018). Vc was used as the standard antioxidant.

118 L9F was separately dissolved in distilled water to prepare flavonoid solutions of different 119 concentrations $(0.01,0.02,0.03 \ldots 0.09$, and $0.10 \mathrm{mg} / \mathrm{mL})$. Two milliliters of ABTS solution was mixed with one hundred Microliters of different flavonoid solution. The mixture incubated in a dark place at room temperature for $6 \mathrm{~min}$. Finally, the absorbance was measured at $734 \mathrm{~nm}$ by a spectrophotometer and each experimental group had 3 parallel controls.

$$
Y(\%)=\left[1-\left(A_{1}-A_{2}\right) / A_{3}\right] \times 100 \%
$$

$\mathrm{Y}(\%)$ is the ABTS radical scavenging activity, $\mathrm{A}_{1}$ is the absorbance of the sample with

ABTS, $A_{2}$ is the absorbance of the sample without ABTS, and $A_{3}$ is the absorbance of ABTS without the sample.

\subsubsection{Hydroxyl radical $(\cdot \mathrm{OH})$ scavenging assay}

The hydroxyl radical scavenging activities of sample was collected as previously described in Chobot (Chobot et al., 2011), and Vc was used as the standard antioxidant. L9F was separately dissolved in distilled water to prepare flavonoid solutions of different 
133

134

135

136

137

138

139

140

141

142

143

144

145

146

147

148

149

150

151

152

153

each concentration was mixed with $1 \mathrm{~mL}$ of Salicylic acid $(6 \mathrm{mM}), 1.5 \mathrm{~mL}$ of phosphate buffer solution (PBS, 0.15 M, pH 7.4), $1 \mathrm{~mL}$ of ferrous sulfate $(6 \mathrm{mM})$ and $0.5 \mathrm{~mL}$ of $\mathrm{H}_{2} \mathrm{O}_{2}$ solution $(0.01 \%)$. Then, the mixtures were incubated at $37^{\circ} \mathrm{C}$ for $30 \mathrm{~min}$. Finally, the absorbance was measured at $510 \mathrm{~nm}$ by a spectrophotometer and each experimental group had 3 parallel controls.

$$
\mathrm{Y}(\%)=\left[\left(\mathrm{A}_{1}-\mathrm{A}_{2}\right) /\left(\mathrm{A}_{3}-\mathrm{A}_{2}\right)\right] \times 100 \%
$$

$\mathrm{Y}(\%)$ is the $\cdot \mathrm{OH}$ radical scavenging activity $(\%), \mathrm{A}_{1}$ is the absorbance of the sample after reaction with hydroxyl radicals, $A_{2}$ is the absorbance of the sample, and $A_{3}$ is the absorbance without $\mathrm{H}_{2} \mathrm{O}_{2}$.

\subsubsection{Superoxide radical $\left(\bullet \mathrm{O}^{2-}\right)$ scavenging assay}

The superoxide radical scavenging activities of sample was collected as previously described in Zhishen and Leong (Zhishen et al., 1999; Leong et al., 2008). Similarly, Vc was used as the standard antioxidant. L9F were separately dissolved in distilled water to prepare polysaccharide solutions of different concentrations $0.01,0.02,0.03 \ldots 0.09$, and $0.10 \mathrm{mg} / \mathrm{mL}$ ). A $1.0 \mathrm{~mL}$ sample of each concentration was mixed with $3.0 \mathrm{~mL}$ of Tris-Hcl buffer ( $\mathrm{pH} 8.2), 0.8 \mathrm{~mL}$ of Pyrogallol $(0.05 \mathrm{M})$. Then, the mixtures were bathed at $25^{\circ} \mathrm{C}$ for $5 \mathrm{~min}$ and $1.0 \mathrm{~mL} \mathrm{HCl}(8.00 \mathrm{M})$ was mixed after that. Finally, the absorbance was measured at $325 \mathrm{~nm}$ using a spectrophotometer.

$$
Y(\%)=\left[1-\left(A_{1} / A_{2}\right)\right] \times 100 \%
$$

$\mathrm{Y}$ is the $\mathrm{O}^{2-}$ radical scavenging activity $(\%), \mathrm{A}_{1}$ is the absorbance of the sample and $\mathrm{A}_{2}$ is the absorbance of the control.

\section{RESULTS}


155

156

157

158

159

160

161

162

3.1 The result of Single factor test

3.1.1The influence of adsorption time

Fig.1 shows that the adsorption ratio increases first and then stabilizes with the increase of adsorption time. The adsorption ratio reached to the maximum first at 1h, which was $59.06 \pm 0.03 \%$.

\subsubsection{The influence of $\mathrm{pH}$}

Fig. 2 shows that the adsorption ratio increases first, then goes down with the increase of $\mathrm{pH}$. The adsorption ratio reach to the maximum at $\mathrm{pH} 3.5$, which was $(31.65 \pm 0.03) \%$. There was no adsorption when $\mathrm{pH}$ was more than 5 , which may be caused by the change of the flavonoid structure and the deactivation (Wu et al., 2017) or the weakening of the adsorption capacity of the macroporous resin (Li et al., 2007) under this $\mathrm{pH}$ condition.

\subsubsection{The effect of temperature}

Fig.3 shows that the adsorption ratio increases first and then goes down with the increase of temperature. The adsorption ratio reached to the maximum first at $30^{\circ} \mathrm{C}$, which was $51.26 \pm 0.02 \%$.

3.2 Optimization of Extraction Process by Response Surface Methodology

\subsubsection{Selection of analysis factor level}

According to Box-Benhnken's central combination test design principle and singlefactor test results, three factors (temperature, $\mathrm{pH}$, and time) that have significant effects on the extraction of total flavonoid were selected, and the three-factor three-level response is adopted, which is shown in Table 1.

3.2.2 Response surface analysis experiment design scheme 
177

178

179

180

181

182

183

184

185

186

A (temperature), $\mathrm{B}(\mathrm{pH})$, and $\mathrm{C}$ (adsorption time) was taken as independent variables, and Y (total flavonoid adsorption ratio) was taken as the response value. The test plan and results are shown in Table 2.

3.2.3 Establishment and Analysis of Multivariate Quadratic Response Surface Regression Model

Quadratic regression response surface analysis Performs in Table 2, and a multiple quadratic response surface regression model was established: $Y=0.47-0.056 \mathrm{~A}-$ $0.042 \mathrm{~B}+0.031 \mathrm{C}+0.088 \mathrm{AB}-0.043 \mathrm{AC}+4 \times 10^{-4} \mathrm{BC}-0.064 \mathrm{~A}^{2}-0.047 \mathrm{~B}^{2}+0.056 \mathrm{C}^{2}$. The variance analysis of each factor is shown in Table 3.

Table 3 shows that the model is significant $(\mathrm{p}<0.05)$ and the Prob $>F$ value of the decisive factor coefficient such as A (temperature), B (pH), C (adsorption time), AB (interaction between temperature and $\mathrm{pH}$ ), $\mathrm{AC}$ (interaction between temperature and adsorption time) are $0.0008,0.0039,0.0161,0.0004,0.0192(\mathrm{p}<0.05)$, indicating that the model has a good fit. In addition, the factors affecting the extraction ratio of total flavonoid were A (temperature), B ( $\mathrm{pH})$, and $\mathrm{C}$ (adsorption time) in order of magnitude, and the temperature reached a significant level $(\mathrm{p}<0.001)$.

In this experiment, the interaction between $\mathrm{AB}$ and $\mathrm{AC}$ has significant effect. The results are shown in Fig.4 and Fig.5, and the interaction between BC is shown in Fig.6. It can be seen from the response surface diagram that the extraction ratio of total flavonoid first increases and then decreases and increases in the end with the increase of $\mathrm{A}$ (temperature). $\mathrm{B}$ is in the range of -1.0 to 0 . Due to the interaction of $\mathrm{A}$, the extraction ratio of total flavonoid is higher. $\mathrm{C}$ is in the range of 0 to 1.0 , due to the interaction of $\mathrm{A}$, the extraction ratio of total flavonoid is higher. 
200

201

202

203

204

205

206

207

208

209

210

211

212

213

214

215

216

217

218

219

220

221

222

\subsubsection{Model verification}

It is obtained that the supreme extraction ratio predicted is $64.2 \%$ under the process conditions of $25.02^{\circ} \mathrm{C}$, pH 2.80 and $1.85 \mathrm{~h}$ by solving the inverse matrix of the quadratic polynomial mathematical model of the total flavonoid yield, .

The optimal conditions were revised to $25^{\circ} \mathrm{C}, \mathrm{pH} 2.80$, and $1.85 \mathrm{~h}$ to extract the total flavonoid by the above to check the validity. The actual adsorption ratio was $(64.14 \pm$ $0.04) \%$, which is close to the theoretical value.

\subsection{The effect of eluent concentration}

Fig.7 shows the ethanol elution effect with different volume fractions. As the volume fraction of the ethanol increases, the elution ratio is increasing. When $60 \%$ ethanol was used, the elution ratio of total flavonoid reached to $(81.54 \pm 0.03) \%$, and the purity of flavonoid was $7.13 \%$. When $80 \%$ ethanol was used, although the elution ratio rises to $(90.49 \pm 0.03) \%$, the purity dropped to $3.61 \%$. Therefore $60 \%$ ethanol is selected for elution considering the purity and elution ratio.

The total flavonoid prepared by ethyl acetate extraction method, whose purity is $14.1 \%$, but extraction ratio is only $(31.68 \pm 0.04) \%$, not only consumes a large amount of raw material and ethyl acetate, but also causes environmental problems. Certain pollution. The macroporous resin adsorption method is more economical and environmentally friendly, and the eluate's purity can rise to $13.69 \%$ with precipitated by absolute ethanol.

\subsection{In vitro antioxidant activity}

3.4.1 DPPH radical scavenging assay

DPPH has been widely accepted as a tool for estimating the free radical scavenging activities of antioxidants (Khled Khoudja et al., 2014). Fig.8 shows that the DPPH clearance ratio goes up 
223 as the concentration of each sample increases and it tends to be flat when the sample mass 224 concentration is greater than $0.05 \mathrm{mg} / \mathrm{mL}$. When the concentration reaches the maximum $(0.1$ $225 \mathrm{mg} / \mathrm{mL})$, the clearance ratio of total flavonoid on DPPH increases from $(95.33 \pm 0.01) \%$ to $226(96.44 \pm 0.04) \%$ after purification, and Vc's clearance ratio is $(94.18 \pm 0.002) \%$. It can be seen 227 that the clearance effect of flavonoid on DPPH slightly better than that before purification, and 228 the clearance effect of flavonoid on DPPH is close to Vc.

229 3.4.2 ABTS radical scavenging assay

230 ABTS has been widely accepted as a tool for estimating the free radical scavenging activities 231 of antioxidants (Thaipong et al., 2012). Fig.9 shows that the ABTS clearance ratio goes up as the

232

233

234

235

236

237

238

239

240

241

242

243

244

245

mass concentration of each sample increases. When the concentration reaches the maximum $(0.1$ $\mathrm{mg} / \mathrm{mL})$, the clearance ratio of total flavonoid on ABTS increases from $(74.06 \pm 0.04) \%$ to $(75.33 \pm 0.03) \%$ after purification, and Vc's clearance ratio is $(71.74 \pm 0.05) \%$. It can be seen that the clearance effect of flavonoid on ABTS slightly better than that before purification, and the clearance effect of flavonoid on ABTS is better than Vc.

\subsubsection{Hydroxyl radical $(\cdot \mathrm{OH})$ scavenging assay}

Hydroxyl radicals are very active that has been associated with cancer risk when it accumulated in the body excessively (Sakanaka et al., 2005). Fig.10 shows that the $\cdot \mathrm{OH}$ clearance ratio goes up as the mass concentration of each sample increases and it tends to be flat when the sample mass concentration is greater than $0.3 \mathrm{mg} / \mathrm{mL}$, but the clearance ratio of the sample before purification shows a downward trend, which may be the presence of oxidized and discolored impurities in the original fermentation broth. When the sample concentration reaches the maximum $(1 \mathrm{mg} / \mathrm{mL})$, the clearance ratio of total flavonoid on $\mathrm{OH}$ increases from $(3.98 \pm 0.02) \%$ to $(73.79 \pm 0.02) \%$ after purification, 
246 and Vc's clearance ratio is $(93.72 \pm 0.01) \%$. It can be seen that the clearance effect of

247 flavonoid on $\cdot \mathrm{OH}$ better than that before purification.

248 3.4.3 Superoxide radical $\left(\bullet \mathrm{O}^{2-}\right)$ scavenging assay

249 Superoxide radical is known to be very harmful to cellular components as a precursor 250 of more reactive oxygen species, contributing to tissue damage and various diseases 251 (Ozsoy et al., 2008; Aruoma et al., 2006). Fig.11 shows that the $\cdot \mathrm{O}^{2-}$ clearance ratio goes

252

253

254

255

256

257

258

259

260

261

262

263

264

265

266

267

268

up as the mass concentration of each sample increases and it tends to be flat when the sample mass concentration is greater than $0.05 \mathrm{mg} / \mathrm{mL}$, but the clearance ratio of the sample before purification shows a downward trend, which may be the presence of oxidized and discolored impurities in the original fermentation broth. When the sample concentration reaches the maximum $(0.1 \mathrm{mg} / \mathrm{mL})$, the clearance ratio of total flavonoid on $\cdot \mathrm{O}^{2-}$ increases from $(0.15 \pm 0.016) \%$ to $(28.11 \pm 0.01) \%$ after purification, and Vc's clearance ratio is $(31.14 \pm 0.01) \%$. It can be seen that the clearance effect of flavonoid on - $\mathrm{O}^{2-}$ better than that before purification.

\section{DISCUSSION}

Flavonoid has attracted more and more attention because of its complex structure and function in these years (Baran et al., 2020; Zou et al., 2020; Xiao-Hui et al., 2020). However, flavonoid from plants is mainly used in the market now. The regeneration ratio is affected by the natural growth of plants, and the yield is limited. Therefore, the objective of this study was to extract flavonoid by macroporous resin and analyse antioxidant activities.

It has been shown that the extraction procedure has a significant impact on the yield and structural characteristics of flavonoid, as well as their biological activities (Taghinia 
269 et al., 2019). The macroporous resin adsorption method has been widely used in the 270 extraction and purification of total flavonoid from plants (Du et al., 2012; Lihu et al., 2018).

271 The macroporous resin adsorption method is more economical and environmentally 272 friendly with similar purity and higher extraction ratio compared with commonly used 273 organic solvent method.

274 It has been found that the generation of reactive oxygen species (ROS) and the corresponding 275 response to oxidative stress are critical factors in the outbreak of several human diseases (Lee \& Lee, 2006). Antioxidants have vital functions against ROS in the biological system (Zhang et al., 2015). In the present study, the Antioxidant activity of flavonoid was studied by DPPH, ABTS, superoxide radical and hydroxyl radicals. The results showed that flavonoid exhibited stronger antioxidant activity than before against DPPH, ABTS, superoxide radical and hydroxyl radicals, and the clearance ratio is highly closed to total flavonoid isolated by ethyl acetate (Tang et al., 2020). the antioxidant research, L9F-M has good antioxidant activity in vitro. These results demonstrate 
292 that macroporous resin in the extraction of total flavonoid from endophytic fungus is better than

293 organic solvents with higher extraction ratio, safety, lower cost and good antioxidant, which

294 provides more evidence for the production of flavonoid by biological fermentation method.

295 However, the further application remain to be explored in future studies.

296 ADDITIONAL INFORMATION AND DECLARATIONS

297 Funding

298 We gratefully acknowledge financial support for this work from Application Fundamentals

(Key) R\&D Project of Sichuan Provincial Science and Technology Department (Grant No. 2019YJ0549), Seedling Project Cultivation Project(Grant No. 2019058) and Key R\&D Project of

Sichuan Provincial Department of Science and Technology(Grant No. 2019YFG0154).

302

303

\section{Conflicts of Interest}

The authors declare no conflicts of interest.

\section{Author Contributions}

- Shuheng Zhao conceived and designed the experiments, performed the experiments, and prepared figures and/or tables.

- Xulong $\mathrm{Wu}$ performed the experiments, analyzed the data, prepared figures and/or tables.

- Xiaoyu Duan, Caixia Zhou, Zhiqiao Zhao performed the experiments, prepared figures and/or tables.

- Zizhong Tang conceived and designed the experiments, drafted the work, approved the final work.

- Hui Chen, Yujun Wan, Yirong Xiao, Hong Chen analyzed the data, drafted the work or revised 
313 it critically for important content.

\section{REFERENCES}

315 Akubugwo IE, Obasi NA, Chinyere GC, and Ugbogu AE. 2007. Nutritional and chemical value 316 of Amaranthus hybridus L. leaves from Afikpo, Nigeri. African Journal of Biotechnology 6(24):2833-2839. DOI: 10.5897/ajb2007.000-2452

Yonekura-Sakakibara K, Higashi Y, Nakabayashi R. 2019. The Origin and Evolution of Plant Flavonoid Metabolism. Other 10:943. DOI: 10.3389/fpls.2019.00943

320

321

322

323

324

325

326

327

328

329

330

Echeverría Javier, Julia O, Leonora M, Urzúa Alejandro, Marcela W.. 2017. Structure-Activity and Lipophilicity Relationships of Selected Antibacterial Natural Flavones and Flavanones of Chilean Flora. Molecules 22(4):608. DOI: 10.3390/molecules22040608

Zhu H, Zhang Y, Ye G, Li Z, Zhou P, Huang C. 2009. In Vivo and in Vitro Antiviral Activities of Calycosin-7-O- $\beta$-D-glucopyranoside against Coxsackie Virus B3. Biological \& Pharmaceutical Bulletin 32(1):68-73. DOI: 10.1248/bpb.32.68

Kamrani Y Y, Amanlou M, Esmaeelian B, Bidhendi S M, Sahebjamei M. 2007. Inhibitory Effects of a Flavonoid-Rich Extract of Pistacia vera Hull on Growth and Acid Production of Bacteria Involved in Dental Plaque. International Journal of Pharmacology 3(3). DOI: 10.3923/ijp.2007.219.226

Gadkowski W, Siepka M, Janeczko T, Kostrzewa-Susow E, Popoński J, Mazur M, Arowska B, Aba W, Maciejewska G, Wawrzeńczyk C. 2019. Synthesis and Antimicrobial Activity of Methoxy- Substituted $\gamma$-Oxa- $\varepsilon$-lactones Derived from Flavanones. Molecules 24(22). DOI: $10.3390 /$ molecules 24224151

Martin U, Romina G, Priscila C. 2013. Endophytic fungi from Peruvian highland and lowland 
335

336

337

338

339

340

341

342

343

344

345

346

347

348

349

350

351

352

353

354

355

356

357

habitats form;distinctive and host plant-specific assemblages. Biodiversity \& Conservation 22(4):999-1016. DOI: 10.1007/s10531-013-0464-X

Carroll G.C, Carroll F.E. 1978. Studies on the incidence of coniferous needle endophytes in the Pacific Northwest. Canadian Journal of Botany 56(24):3034-3043. DOI: 10.1139/b78-367

Qiu M, Xie R S, Shi Y, Zhang H, Chen HM. 2010. Isolation and identification of two flavonoidproducing endophytic fungi from Ginkgo biloba L.. Annals of Microbiology. DOI: $10.1007 / \mathrm{s} 13213-010-0016-5$

Shih T C, Tian X, Huang C, Huang J 2017. Identification of flavonoids and flavonoid-producing endophytic fungi isolated from opisthopappus. Bangladesh Journal of Botany 46(3):10631070.

Shou-Jie L, Xuan Z, Xiang-Hua W, Chang-Qi Z. 2019. Novel natural compounds from endophytic fungi with anticancer activity. European Journal of Medicinal Chemistry :316343. DOI: 10.1016/j.ejmech.2018.07.015

Chi W C, Pang K L, Chen W L, Wang G J, Lee T H. 2019. Antimicrobial and iNOS inhibitory activities of the endophytic fungi isolated from the mangrove plant Acanthus ilicifolius var. xiamenensis. Botanical Studies 60(1). DOI: 10.1186/s40529-019-0252-3

Tang Z, Wang Y, Yang J, Xiao Y, Wang G. 2020. Isolation and identification of flavonoidproducing endophytic fungi from medicinal plant Conyza blinii H.Lév that exhibit higher antioxidant and antibacterial activities. PeerJ 8:e8978. DOI: 10.7717/peerj.8978

Du H, Wang H, Yu J, Liang C, Li P. 2012. Enrichment and Purification of Total Flavonoid CGlycosides from Abrus mollis Extracts with Macroporous Resins. Industrial \& Engineering Chemistry Research 51(21):7349-7354. DOI: 10.1021/ie3004094

Li J, Chen Z, Di D. 2012. Preparative separation and purification of Rebaudioside A from Stevia 
358

359

360

361

362

363

364

365

366

367

368

369

370

371

372

373

374

375

376

377

378

379

380

rebaudiana Bertoni crude extracts by mixed bed of macroporous adsorption resins. Food Chemistry 132(1):268-276. DOI: 10.1016/j.foodchem.2011.10.077

Chen Z, Long J, Kang L, Du X, Di D. 2013. Modified macroporous adsorption resin (LX1180) used to adsorb flavonoid. Pigment \& Resin Technology 42(6). DOI: 10.1108/PRT-04-20120030

Zhang L, Wu T, Wang Z, Ding G, Zhao L. 2018. Enrichment and Purification of Total Ginkgo Flavonoid O-Glycosides from Ginkgo Biloba Extract with Macroporous Resin and Evaluation of Anti-Inflammation Activities In Vitro. Molecules 23(5):1167. DOI: 10.3390/molecules23051167

Saraswaty V, Srikandace Y, Simbiyani N A, Jasmansyah, Udin Z. 2013. Antioxidant activity and total phenolic content of endophytic fungus Fennellia nivea NRRL 5504.. Pakistan Journal of Biological ences Pjbs 16(22):1574-8. DOI: 10.3923/pjbs.2013.1574.1578

Tao J, Wei Y, Hu T. 2015. Flavonoids of Polygonum hydropiper L. attenuates lipopolysaccharide-induced inflammatory injury via suppressing phosphorylation in MAPKs pathways.. Bmc Complementary \& Alternative Medicine 16(1):1-15. DOI: $10.1186 / \mathrm{s} 12906-016-1001-8$

Bi Y G, Tan Y Q. 2012. Study on Macroporous Resin Separation and Purification of Total Flavonoids of Plantago Process. Advanced Materials Research 550-553:987-992. DOI: 10.4028/www.scientific.net/AMR.550-553.987

Zhang L, Wu T, Wei X, Wang Z, Ding G, Zhao L. 2018. Enrichment and Purification of Total Ginkgo Flavonoid O-Glycosides from Ginkgo Biloba Extract with Macroporous Resin and Evaluation of Anti-Inflammation Activities In Vitro. Molecules 23(5):1167. DOI: $10.3390 /$ molecules 23051167 
381

382

383

384

385

386

387

388

389

390

391

392

393

394

395

396

397

398

399

400

401

402

403

Yu M, Wang B, Qi Z, Xin G, Li W. 2019. Response Surface Method Was Used to Optimize the Ultrasonic Assisted Extraction of Flavonoids from Crinum asiaticum. Saudi Journal of Biological Sciences 26(8). DOI: 10.1016/j.sjbs.2019.09.018

Kaur N, Arora D S, Kalia N, Laur M. 2020. Antibiofilm, antiproliferative, antioxidant and antimutagenic activities of an endophytic fungus Aspergillus fumigatus from Moringa oleifera. Molecular Biology Reports 47(4). DOI: 10.1007/s11033-020-05394-7

Tsimogiannis D I, Oreopoulou V. 2006. The contribution of flavonoid C-ring on the DPPH free radical scavenging efficiency. A kinetic approach for the 3',4'-hydroxy substituted members. Innovative Food science \& Emerging Technologies 7(1-2):140-146. DOI: 10.1016/j.ifset.2005.09.001

Zhang H, Yang Y F, Zhou Z Q. 2018. Phenolic and flavonoid contents of mandarin (Citrus reticulata Blanco) fruit tissues and their antioxidant capacity as evaluated by DPPH and ABTS methods. Journal of Integrative Agriculture 17(1):256-263. DOI: 10.1016/S2095$3119(17) 61664-2$

Chobot V, Hadacek F. 2011. Exploration of pro-oxidant and antioxidant activities of the flavonoid myricetin. Redox Report 16(6):242-247. DOI: $10.1179 / 1351000211 Y .0000000015$

Zhishen J, Mengcheng T, Jianming W. 1999. The determination of flavanoid contents on mulberry and their scavenging effects on superoxide radical. Food Chemistry 64(4):555-559. DOI: 10.1016/S0308-8146(98)00102-2

Leong C N A, Tako M, Hanashiro I, Tamaki H. 2008. Antioxidant flavonoid glycosides from the leaves of Ficus pumila L. Food Chemistry 109(2):415-420. DOI: 10.1016/j.foodchem.2007.12.069 
404 Wu DQ, Ma ZY, Hei JW, Li S. 2017. Antioxidant Stability of flavonoid from Oriental Stephania

405 Root. West China J Pharm SCI 32(5):511-513. DOI: 10.13375/j.cnki.wcjps.2017.05.019

406

407

408

409

410

411

412

413

414

415

416

417

418

419

420

421

422

423

424

425

426

Li YM, Gao J, Yang ZJ, Lin ML. 2007. Studt on the Adsorbing and Refining Alkaloid from Cynanchumkomaroviial.Iljinski with Macro-porous Resin. J Inner Mongolia Univ of Tech: Nat Sci Ed 26(1):38-41. DOI: 10.3969/j.issn.1001-5167-B.2007.01.008

Khled Khoudja N, Boulekbache-Makhlouf L, Madani K. 2014. Antioxidant capacity of crude extracts and their solvent fractions of selected Algerian Lamiaceae. Industrial Crops and Products 52:177-182. DOI: $\quad 10.1016 /$ j.indcrop.2013.10.004

Thaipong K, Boonprakob U, Crosby K, Cisneros-Zevallos L, Byrne DH. 2012. Comparison of ABTS, DPPH, FRAP, and ORAC assays for estimating antioxidant activity from guava fruit extracts. Journal of Food Composition \& Analysis 19(6-7):669-675. DOI: 10.1016/j.jfca.2006.01.003

Sakanaka S, Tachibana Y, Okada Y. 2005. Preparation and antioxidant properties of extracts of Japanese persimmon leaf tea (kakinoha-cha). Food Chemistry 89(4):569-575. DOI:10.1016/j.foodchem.2004.03.013

Ozsoy N, Can A, Yanardag R \& Akev N. 2008. Antioxidant activity of Smilax excelsa L. leaf extracts. Food Chemistry 110(3):571-583. DOI: 10.1016/j.foodchem.2008.02.037

Aruoma OI, Grootveld M, Bahorun T. 2006. Free radicals in biology and medicine: from inflammation to biotechnology. Biofactors 27(1-4):1-3. DOI:10.1002/biof.5520270101

Baran M Y, Güzin Emecen, András Simon, Gábor Tóth, Kuruuzum-Uz A. 2020. Assessment of the antioxidant activity and genotoxicity of the extracts and isolated glycosides with a new flavonoid from Lotus aegaeus (Gris.) Boiss. Industrial Crops and Products 153:112590. DOI: $10.1016 /$ j.indcrop.2020.112590 
427 Zou Y, Xin X, Xu H, Yuan H, Zhao G. 2020. Highly efficient bioconversion of flavonoid 428 glycosides from citrus-processing wastes in solvent-buffer systems. Green Chemistry 22(Pt 429 3). DOI: $10.1039 / \mathrm{D} 0 \mathrm{GC} 00669 \mathrm{~F}$

430 Zhang XH, Shen J, Zhao CC, Shao JH. 2020. A New Flavonoid Glycoside with $\alpha$-Glucosidase 431 Inhibitory Activity from Galium Verum. Chemistry of Natural Compounds 56(1):1-3. DOI: $432 \quad 10.1007 / \mathrm{s} 10600-020-02945-\mathrm{Z}$

433 Taghinia P, Khodaparast M H H, Ahmadi M. 2019. Free and bound phenolic and flavonoid 434 compounds of Ferula persica obtained by different extraction methods and their antioxidant 435 effects on stabilization of soybean oil. Journal of Food Measurement and Characterization 2019(2). DOI: 10.1007/s11694-019-00218-0

437 Lee KW, Lee HJ. 2006. Biphasic effects of dietary antioxidants on oxidative stress-mediated 438 carcinogenesis. Mechanisms of Ageing \& Development 127(5):424-431. DOI: $439 \quad$ 10.1016/j.mad.2006.01.021

440 Zhang $\mathrm{CH}, \mathrm{Yu}$ Y, Liang YZ, Chen XQ. 2015. Purification, partial characterization and 441 antioxidant activity of polysaccharides from Glycyrrhiza uralensis. International Journal of 442 Biological Macromolecules 79:681-686. DOI: 10.1016/j.ijbiomac.2015.05.060 
Figure 1

Relationship between adsorption time and adsorption rate

The data point indicates the change of adsorption rate over time.

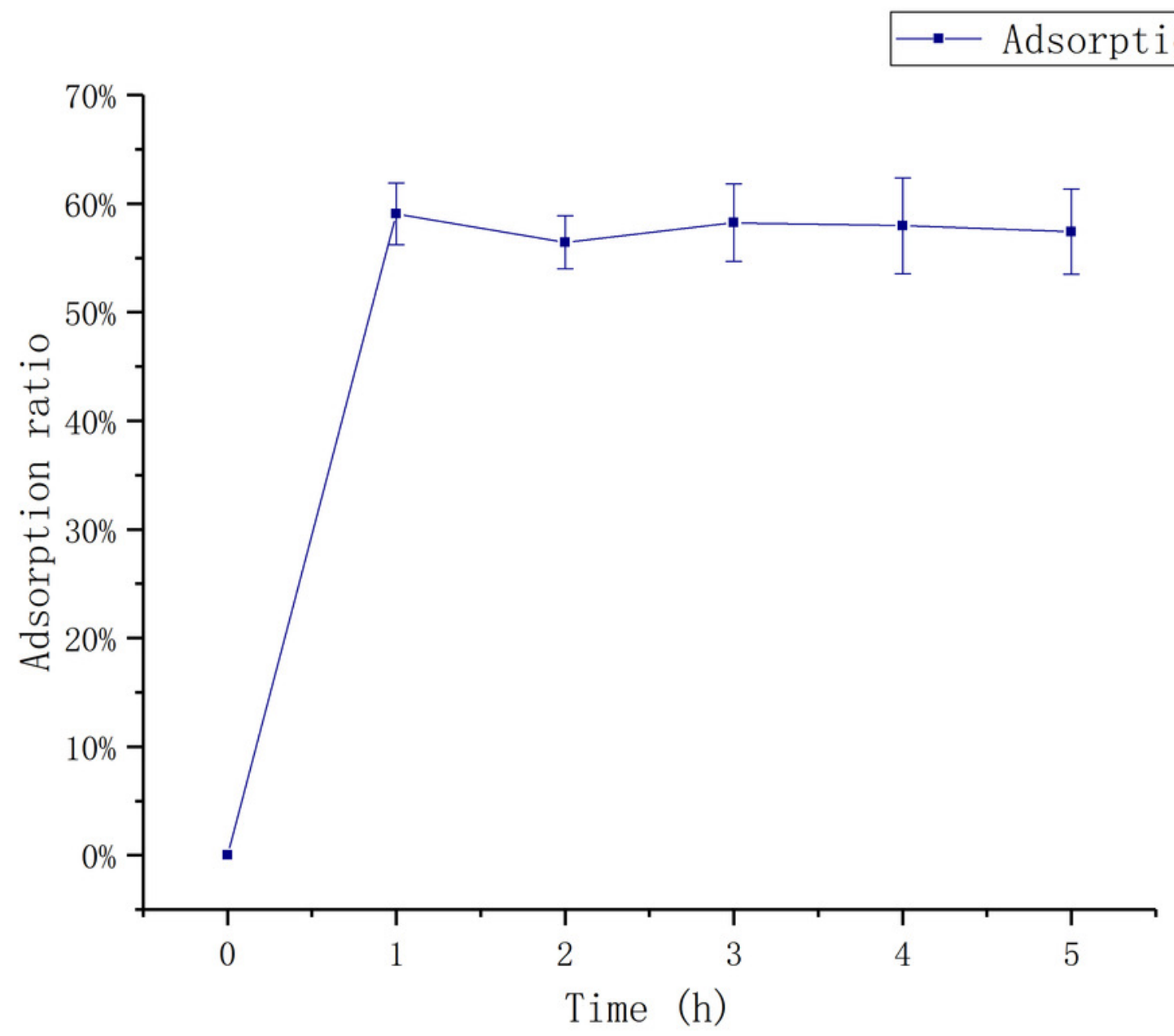


Figure 2

\section{Adsorption of D101 under different $\mathrm{pH}$ conditions}

The data point indicates the change of adsorption rate over $\mathrm{pH}$.

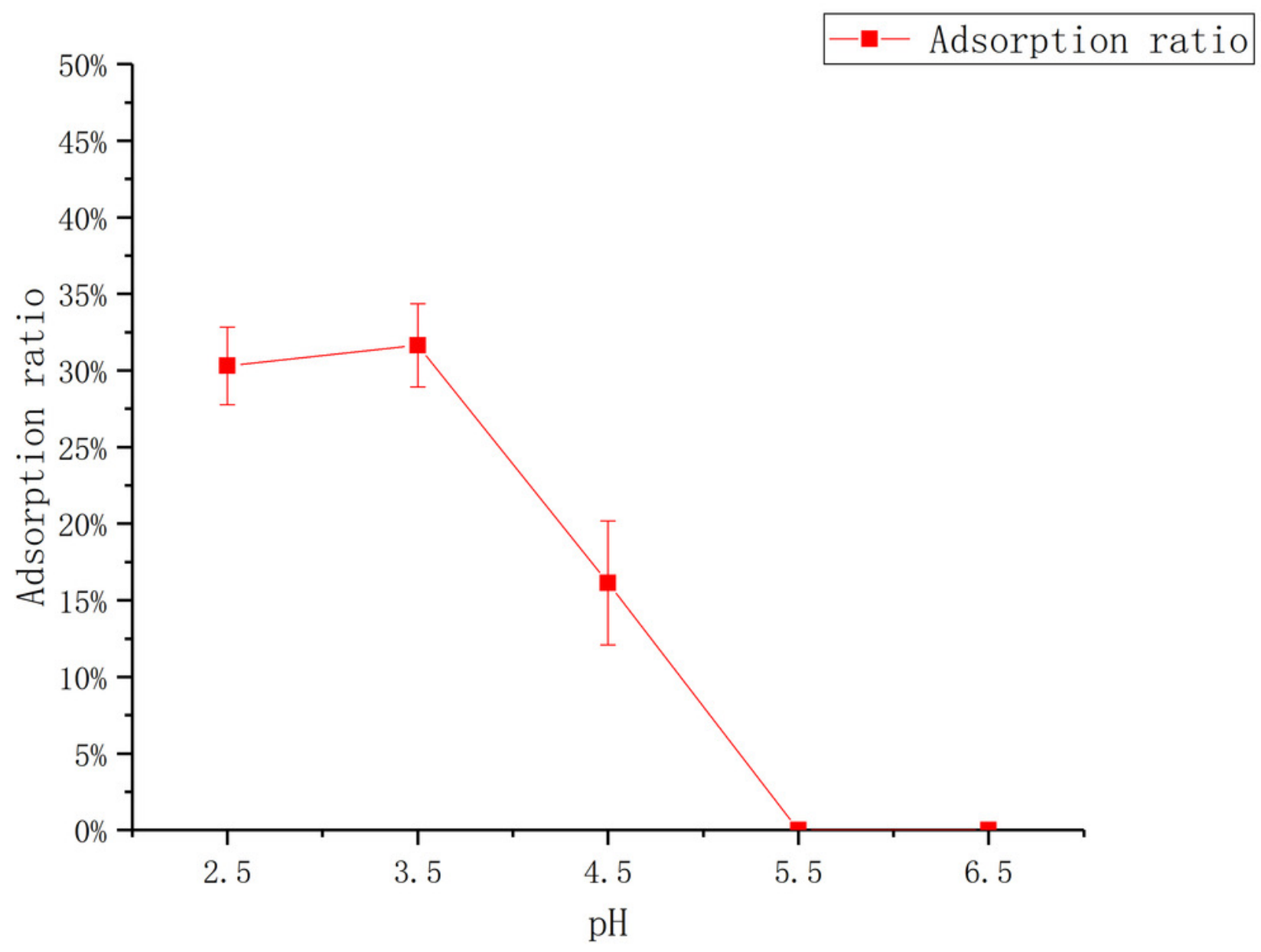


Figure 3

Adsorption of D101 under different liquid temperature

The data point indicates the change of adsorption rate over temperature.

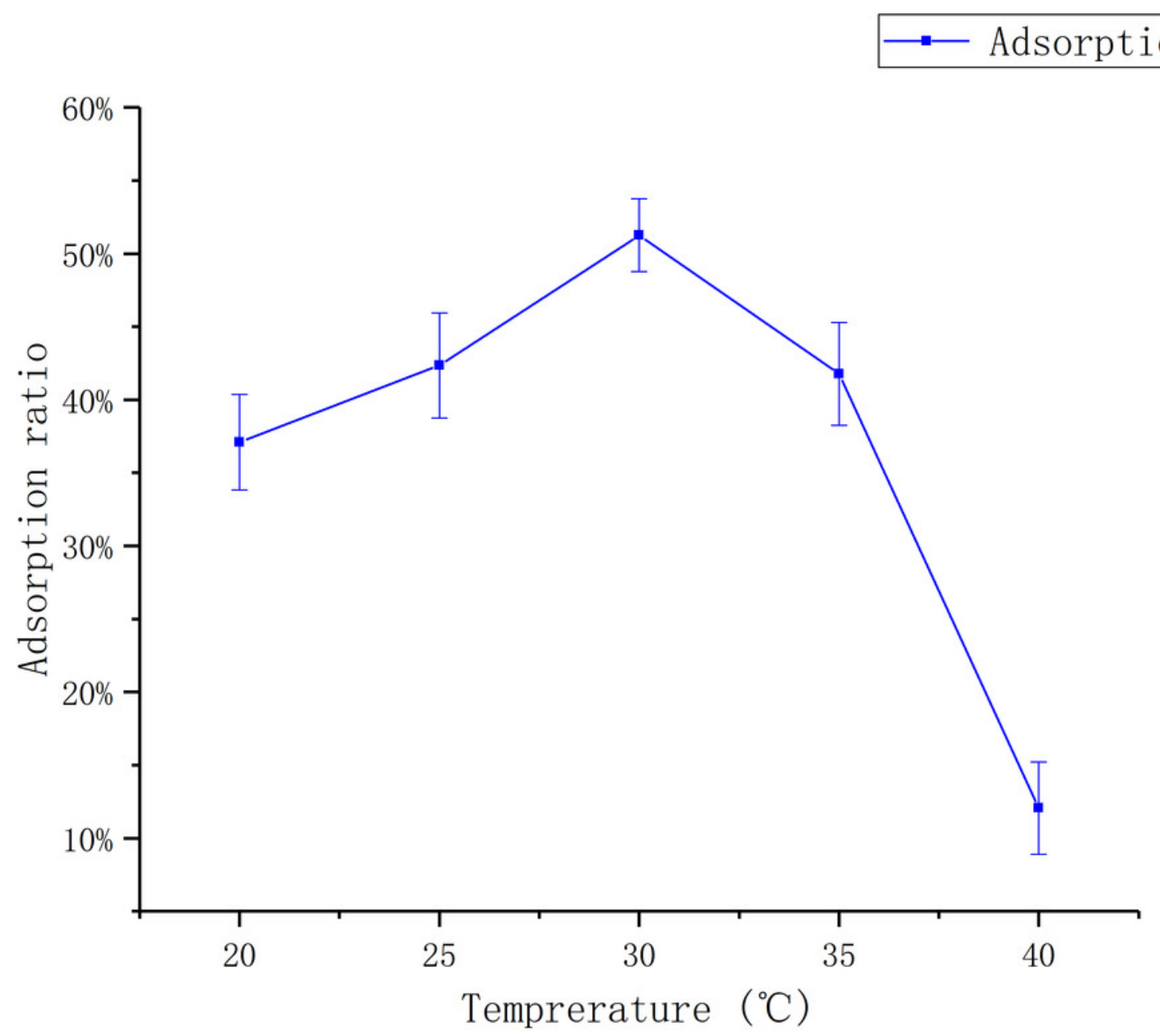


Figure 4

Response Surface of interrelated influence of temperature and $\mathrm{pH}$ to flavonoids rate

Design-Expert?Software

Factor Coding: Actual

Absorption rate

- Design points above predicted value

- Design points below predicted value 0.5625

0.2403

$\mathrm{X} 1=\mathrm{A}:$ Temperature

$\mathrm{X} 2=\mathrm{B}: \mathrm{pH}$

Actual Factor

C: Time $=1$

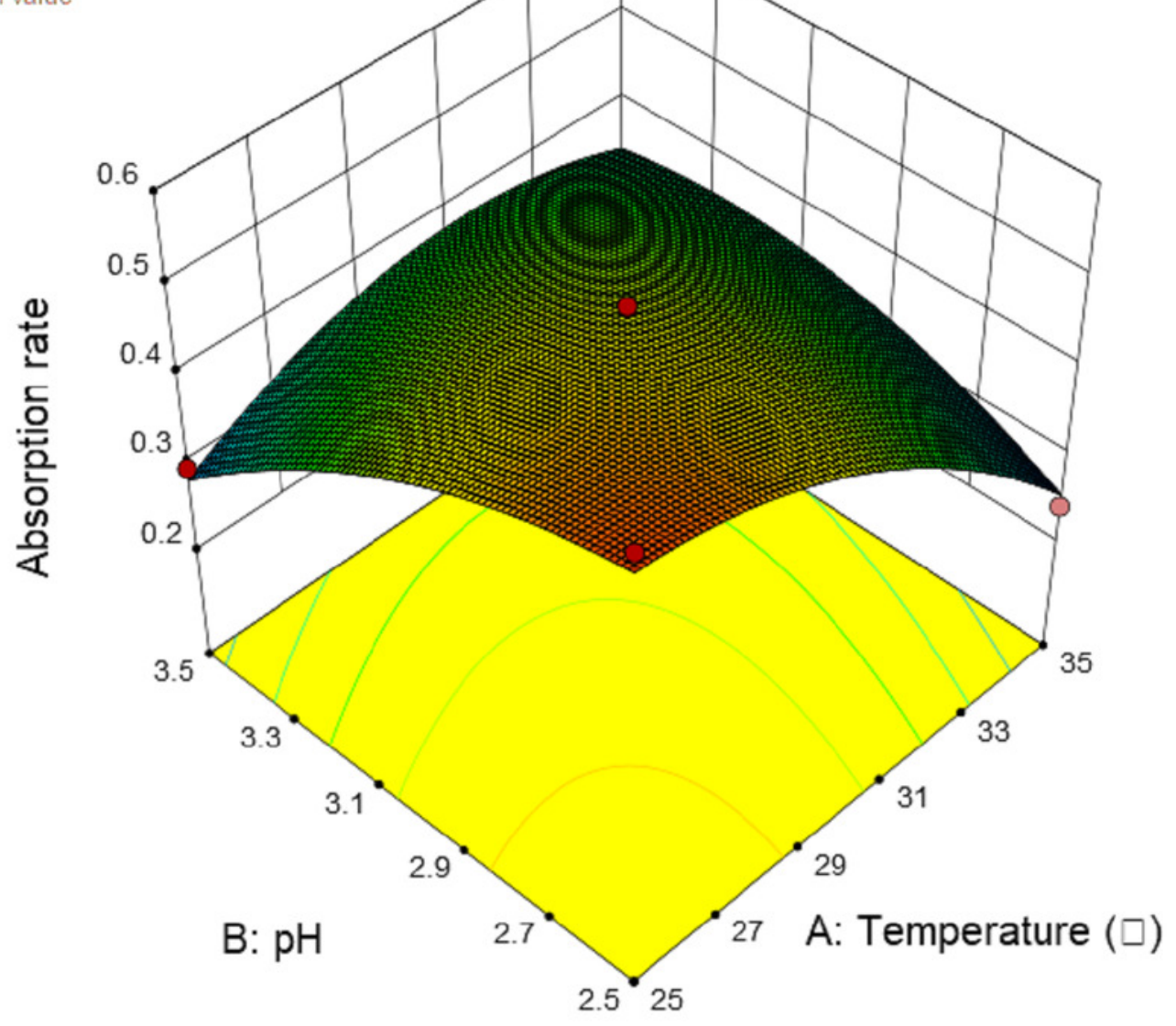




\section{Figure 5}

Response Surface of interrelated influence of temperature and time to flavonoids rate

Design-Expert?Software

Factor Coding: Actual

Absorption rate

0.5625

0.2403

$\mathrm{X} 1=\mathrm{A}:$ Temperature

$\mathrm{X} 2=\mathrm{C}:$ Time

Actual Factor

$\mathrm{B}: \mathrm{pH}=2.97297$

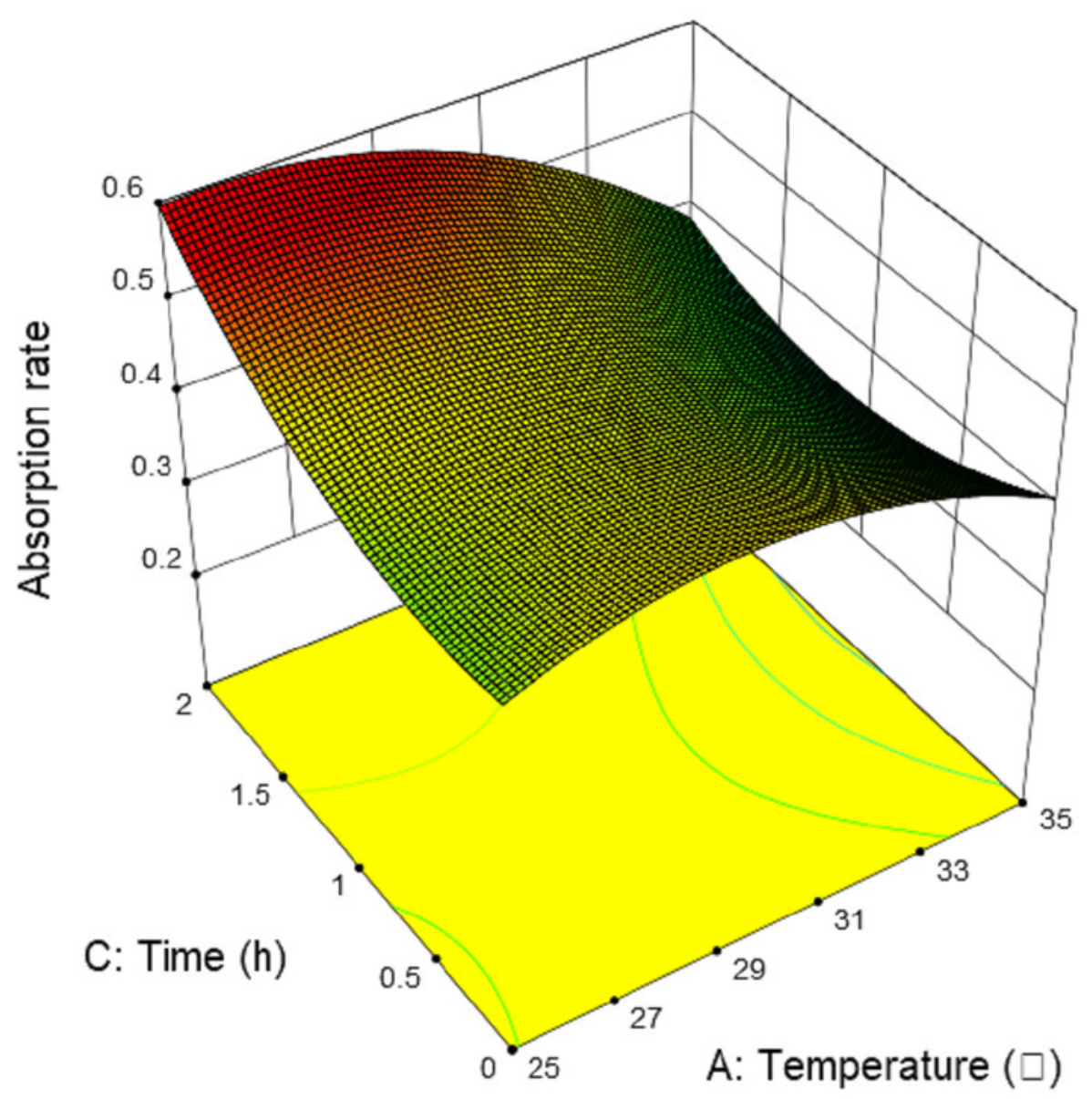


Figure 6

Response Surface of interrelated influence of $\mathrm{pH}$ and time to flavonoids rate

Design-Expert?Software

Factor Coding: Actual

Absorption rate

- Design points above predicted value

- Design points below predicted value

0.5625

0.2403

$\mathrm{X} 1=\mathrm{B}: \mathrm{pH}$

$\mathrm{X} 2=\mathrm{C}:$ Time

Actual Factor

$\mathrm{A}:$ Temperature $=30$

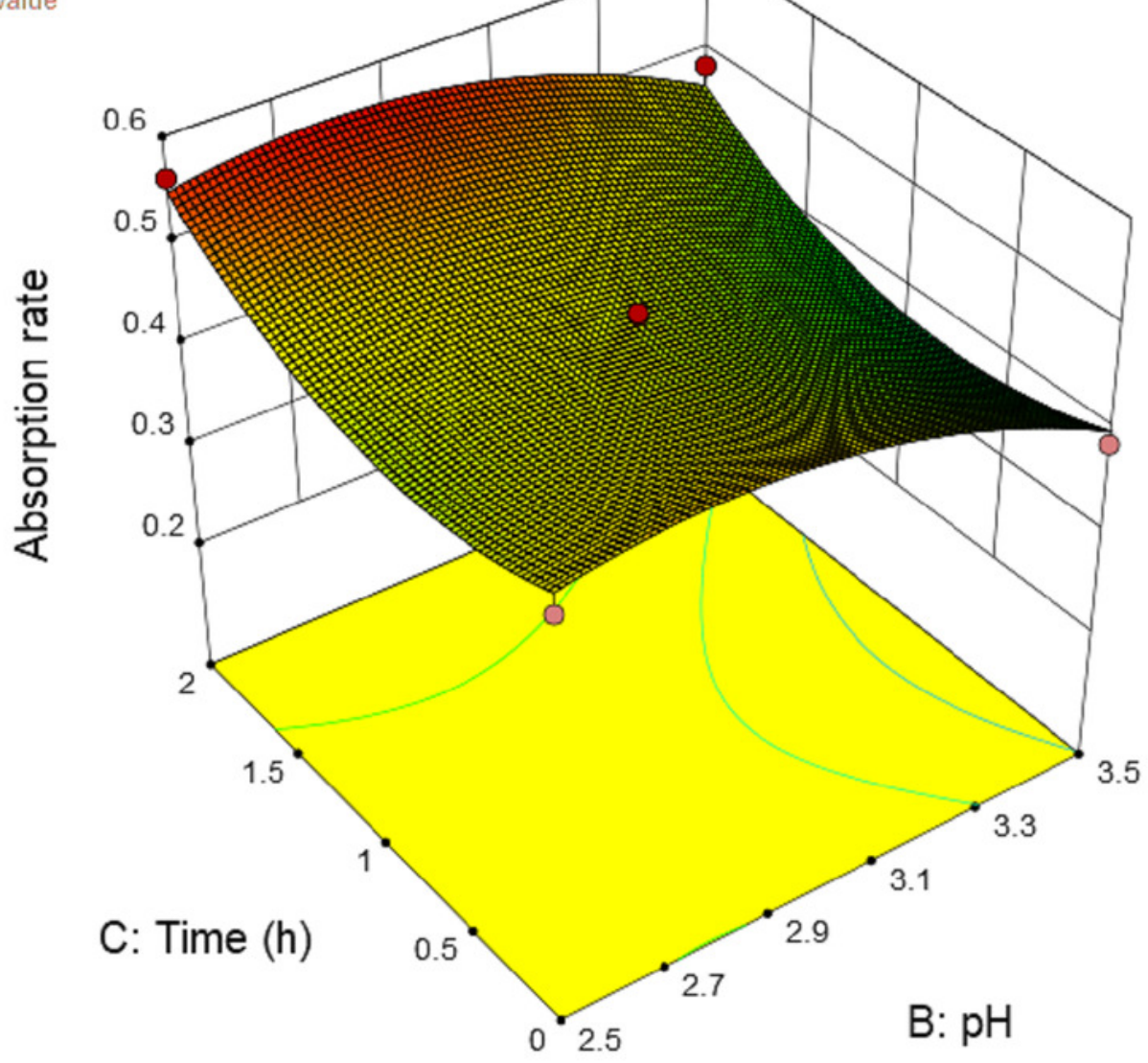


Figure 7

Comparison of elution rate and purity of total flavonoids at different concentrations

The data point indicates the Indicates the change of elution rate and purity of flavonoid over eluent.

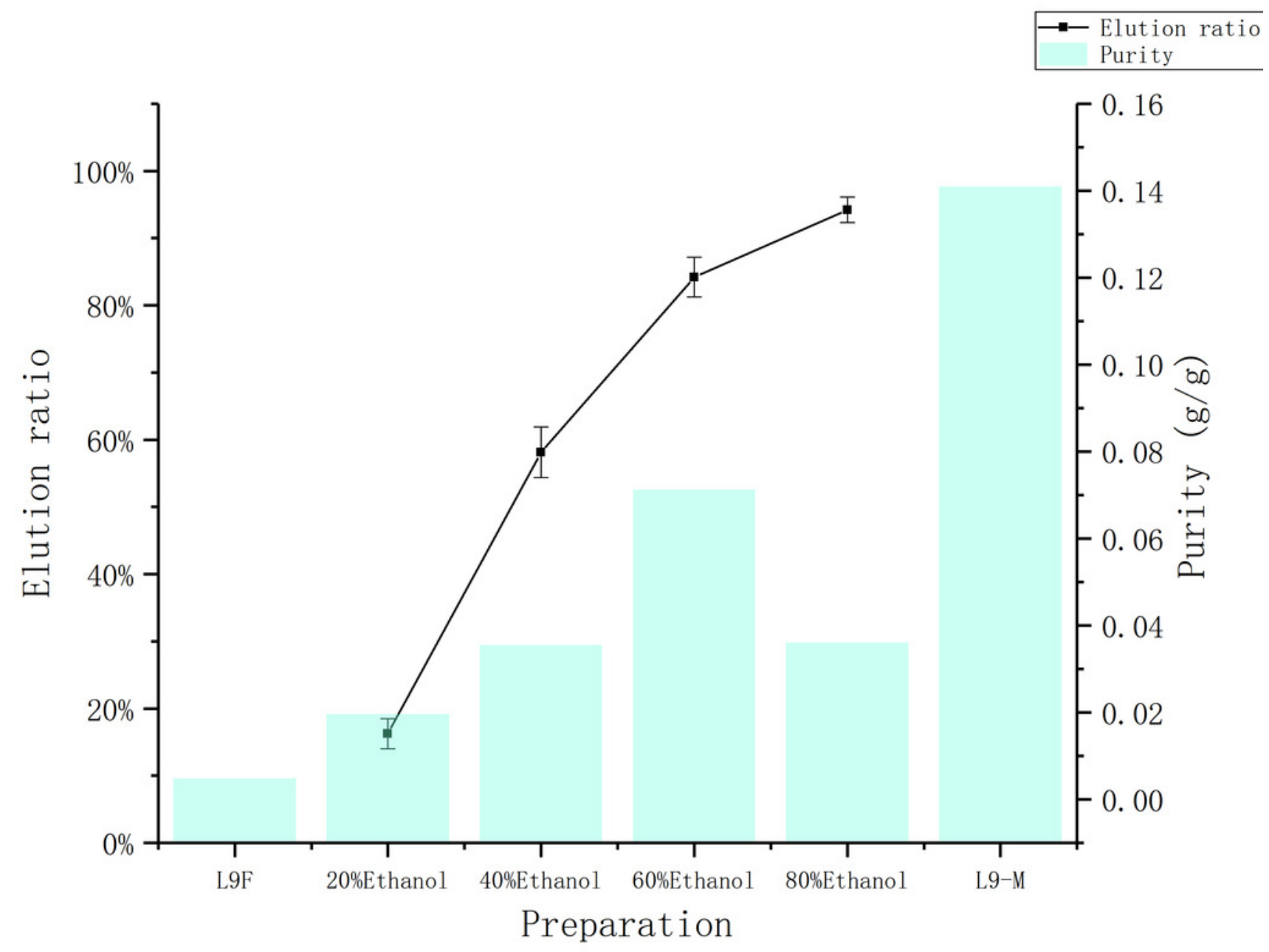


Figure 8

Scavenging ability of total flavonoids of endophytic fungi on DPPH

Each data point indicates the clearance rate of total flavonoids on DPPH before and after extraction $\square$ where $\mathrm{Vc}$ is the control.

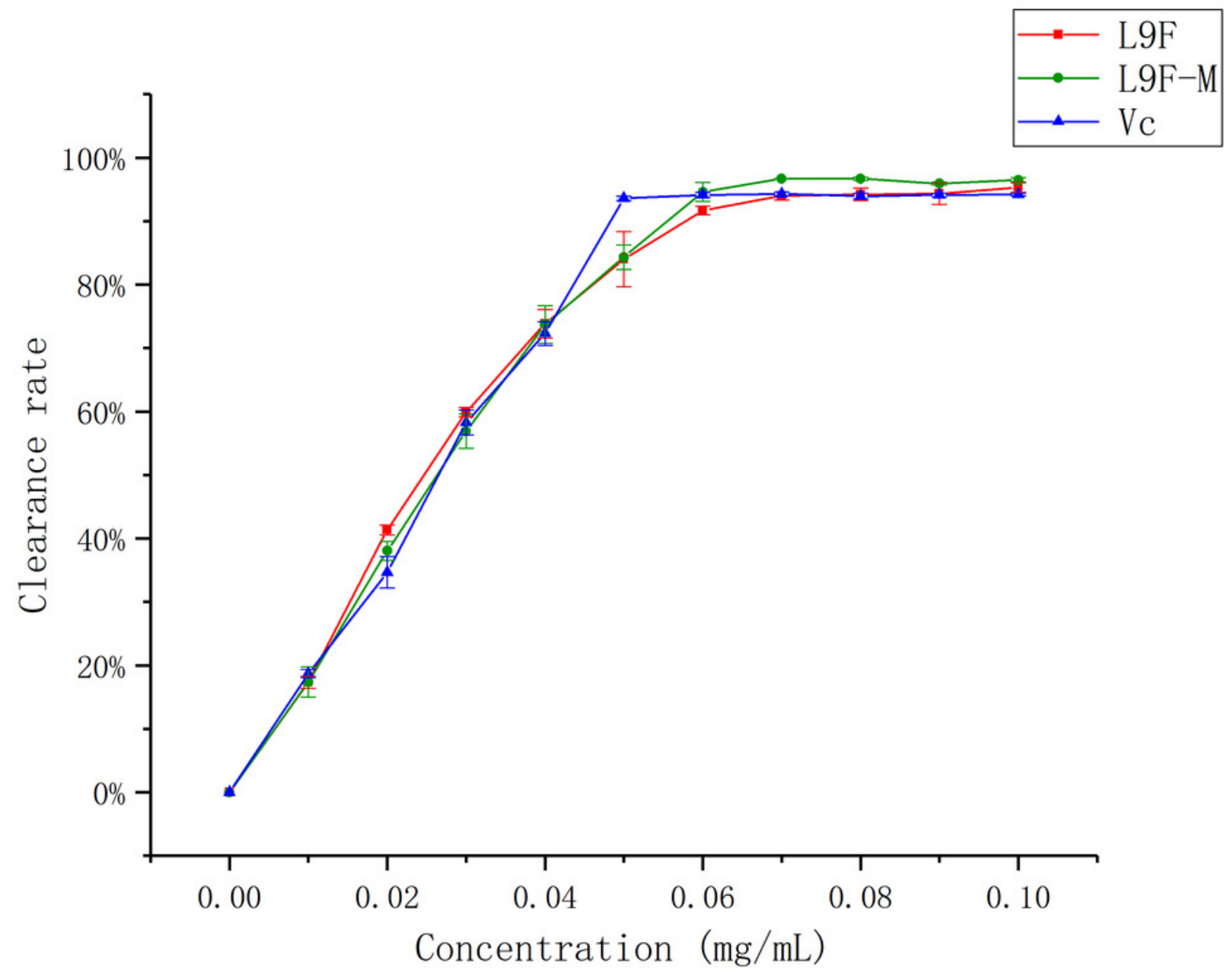


Figure 9

Scavenging ability of total flavonoids of endophytic fungi on ABTS

Each data point indicates the clearance rate of total flavonoids on ABTS before and after extraction $\square$ where $\mathrm{Vc}$ is the control.

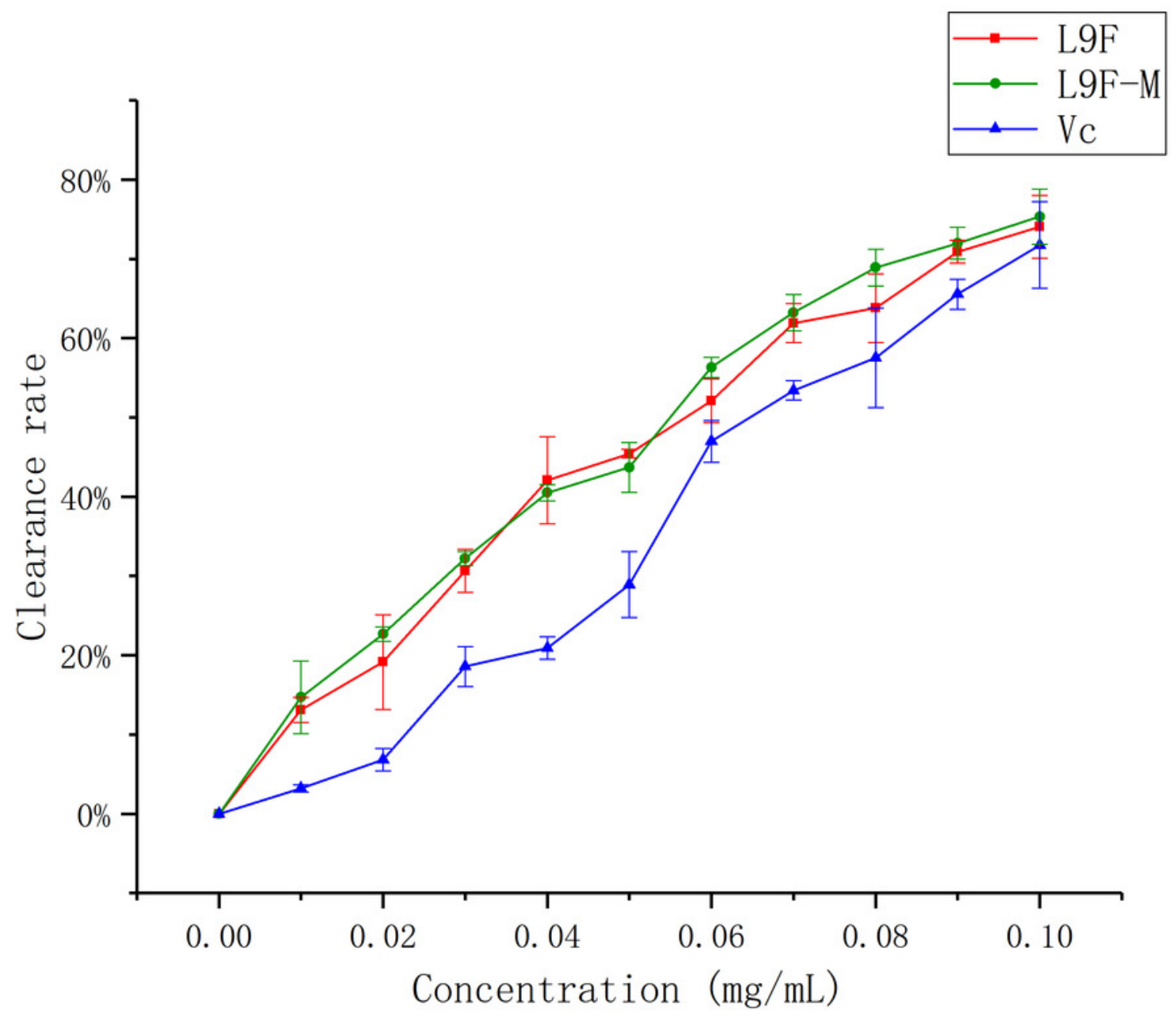


Figure 10

Scavenging ability of total flavonoids of endophytic fungi on $-\mathrm{OH}$

Each data point indicates the clearance rate of total flavonoids on $-\mathrm{OH}$ before and after extraction $\square$ where $V c$ is the control.

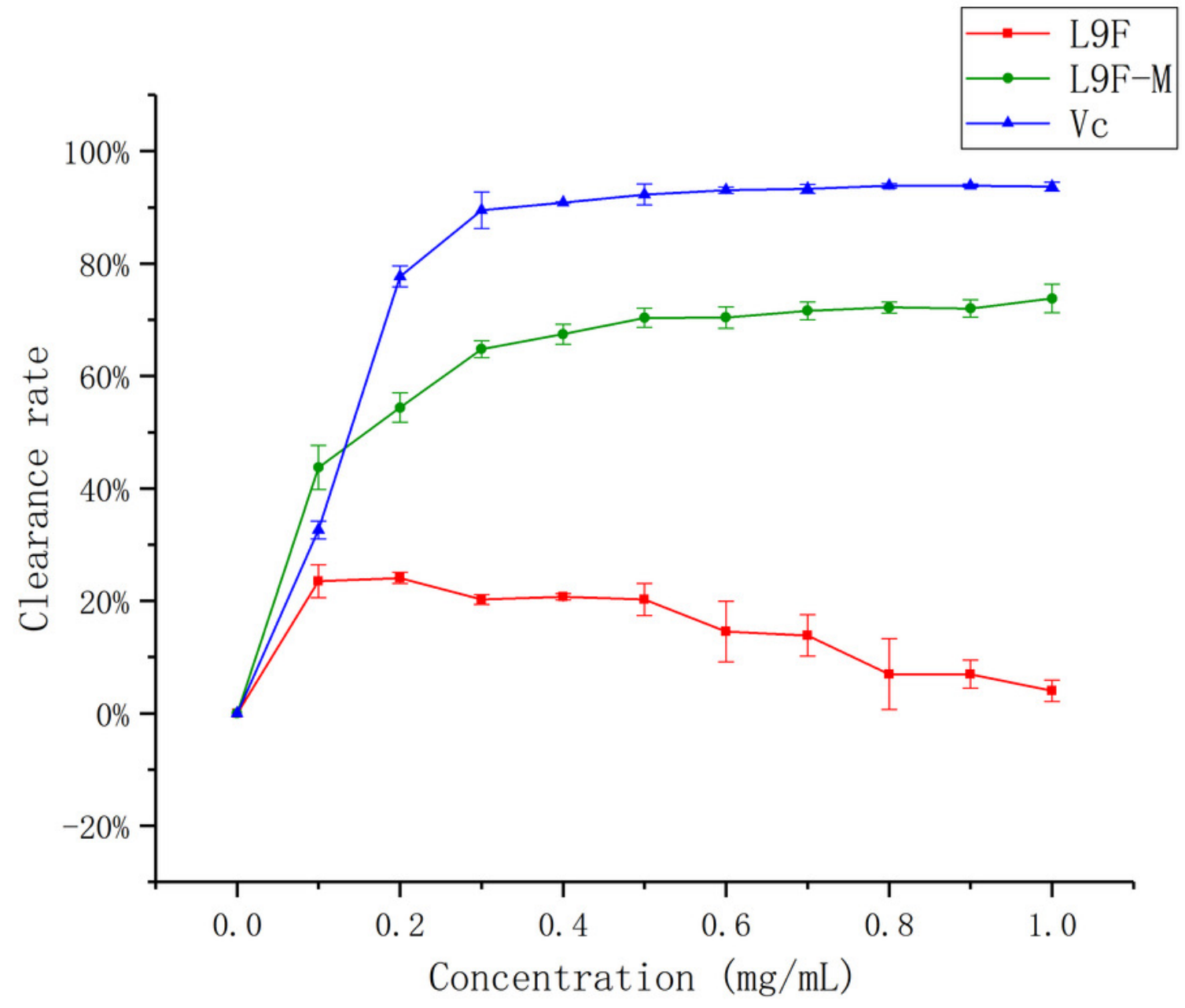


Figure 11

Scavenging ability of total flavonoids of endophytic fungi on $\cdot \mathrm{O}^{2-}$

Each data point indicates the clearance rate of total flavonoids on $\cdot \mathrm{O}^{2-}$ before and after extraction $\square$ where $V_{c}$ is the control.

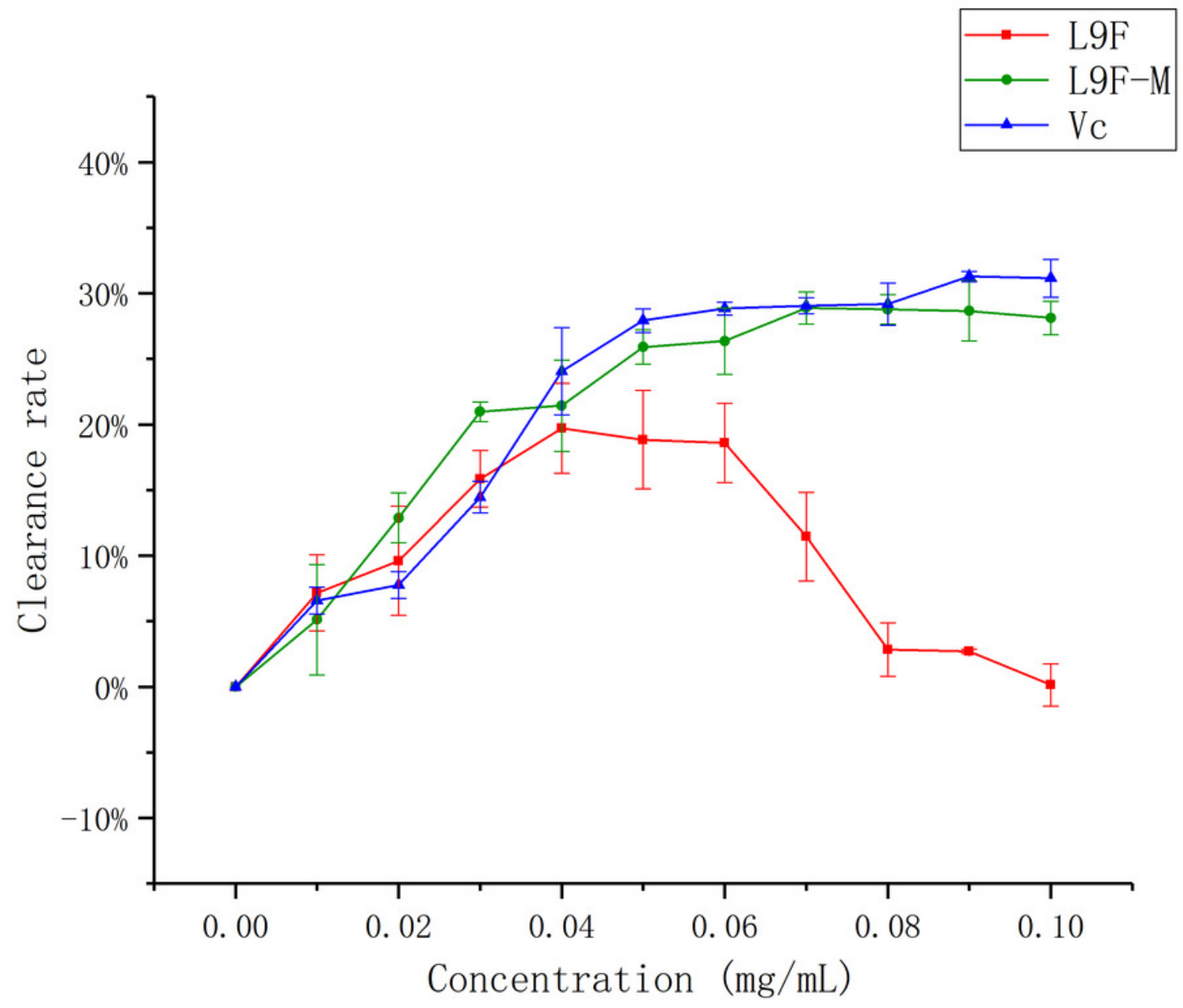




\section{Table 1 (on next page)}

Factors and the levels of experiment of Response Surface Analysis 
Table.1 Factors and the levels of experiment of Response Surface Analysis

\begin{tabular}{cccc}
\hline & \multicolumn{3}{c}{ Factor levels } \\
\cline { 2 - 4 } Factors & -1 & 0 & 1 \\
\hline Temperature $/{ }^{\circ} \mathrm{C}$ & 25 & 30 & 35 \\
$\mathrm{pH}$ & 2.5 & 3.5 & 4.5 \\
time $/ \mathrm{h}$ & 0 & 1 & 2 \\
\hline
\end{tabular}

2 
Table 2 (on next page)

Observed and estimated values for different levels of experimental design 


\begin{tabular}{|c|c|c|c|c|}
\hline \multirow{2}{*}{ No. } & \multicolumn{3}{|c|}{ Factors } & \multirow{2}{*}{ Adsorption rate/\% } \\
\hline & A & $\mathrm{B}$ & $\mathrm{C}$ & \\
\hline 1 & 0 & 0 & 0 & 0.4739 \\
\hline 2 & 0 & 1 & 1 & 0.485 \\
\hline 3 & 0 & 0 & 0 & 0.4709 \\
\hline 4 & 1 & 0 & -1 & 0.448 \\
\hline 5 & 0 & -1 & -1 & 0.4667 \\
\hline 6 & 1 & 1 & 0 & 0.3244 \\
\hline 7 & 1 & -1 & 0 & 0.2403 \\
\hline 8 & -1 & -1 & 0 & 0.5625 \\
\hline 9 & -1 & 0 & -1 & 0.4396 \\
\hline 10 & -1 & 1 & 0 & 0.2957 \\
\hline 11 & 0 & 0 & 0 & 0.4739 \\
\hline 12 & 0 & 0 & 0 & 0.4402 \\
\hline 13 & 0 & 1 & -1 & 0.3885 \\
\hline 14 & 0 & -1 & 1 & 0.5616 \\
\hline 15 & -1 & 0 & 1 & 0.555 \\
\hline 16 & 0 & 0 & 0 & 0.4739 \\
\hline 17 & 1 & 0 & 1 & 0.3927 \\
\hline
\end{tabular}

2 


\section{Table 3(on next page)}

Analyze of mean square

SS means sum of spuares; DF means degree of freedom; MS means mean square; F means a statistic obtained by analysis of variance based on experimental data; Prob $\square \mathrm{F}$ means the chance that an $\mathrm{F}$ this large could occur due to noise. 
1

\begin{tabular}{cccccc}
\hline & & & & & Prob \\
Source & SS & DF & MS & F & $>$ F \\
\hline Model & 0.1236 & 9 & 0.0137 & 17.2796 & 0.0005 \\
A-temperature & 0.0250 & 1 & 0.0250 & 31.4807 & 0.0008 \\
B-pH & 0.0142 & 1 & 0.0142 & 17.9143 & 0.0039 \\
C-time & 0.0079 & 1 & 0.0079 & 9.9478 & 0.0161 \\
AB & 0.0308 & 1 & 0.0308 & 38.7302 & 0.0004 \\
AC & 0.0073 & 1 & 0.0073 & 9.1654 & 0.0192 \\
BC & 0.0000 & 1 & 0.0000 & 0.0008 & 0.9782 \\
A $^{\wedge}$ & 0.0171 & 1 & 0.0171 & 21.5163 & 0.0024 \\
B $^{\wedge}$ & 0.0093 & 1 & 0.0093 & 11.7547 & 0.0110 \\
$\mathrm{C}^{\wedge} 2$ & 0.0132 & 1 & 0.0132 & 16.6103 & 0.0047 \\
Error & 0.0056 & 7 & 0.0008 & & 0.0439 \\
Lack of Fit & 0.0047 & 3 & 0.0016 & 7.1415 & \\
\hline Pure Error & 0.0009 & 4 & 0.0002 & & \\
\hline Total & 0.1292 & 16 & & & \\
\hline
\end{tabular}

Table.3 Analyze of mean square

2

3 